\title{
Socio-Demographic Profile of Adults Admitted in Emergency for Brain Trauma Injuries at the University Hospital of Brazzaville (Congo)
}

\author{
Hugues Brieux Ekouele Mbaki'1, Pascal Diogène Bingui Outman', Marie Elombila1, \\ Darius Eryx Mbou Essie1, Christ Mayick Mpoy Emy Monkessa'2, Rel Gerald Boukaka Kala ${ }^{3}$, \\ Léon Boukassa ${ }^{1}$, Gilbert Fabrice Otiobanda ${ }^{1}$
}

\author{
${ }^{1}$ Faculty of Health Sciences, Marien Ngouabi University, Brazzaville, Congo \\ ${ }^{2}$ Department of Intensive Care, University Hospital of Brazzaville, Brazzaville, Congo \\ ${ }^{3}$ Cheikh Anta Diop University, Dakar, Senegal \\ Email: hugues.ekouele-mbaki@umng.cg
}

How to cite this paper: Mbaki, H.B.E., Outman, P.D.B., Elombila, M., Essie, D.E.M., Monkessa, C.M.M.E., Kala, R.G.B., Boukassa, L. and Otiobanda, G.F. (2019) Socio-Demographic Profile of Adults Admitted in Emergency for Brain Trauma Injuries at the University Hospital of Brazzaville (Congo). Open Journal of Modern Neurosurgery, 9, 43-48.

https://doi.org/10.4236/ojmn.2019.91006

Received: November 27, 2018

Accepted: December 25, 2018

Published: December 28, 2018

Copyright ( 92019 by authors and Scientific Research Publishing Inc. This work is licensed under the Creative Commons Attribution International License (CC BY 4.0).

http://creativecommons.org/licenses/by/4.0/ cc) (i) Open Access

\begin{abstract}
The aim of this study was to evaluate socio-demographic profile of adults admitted in emergency for Traumatic Brain Injury (TBI) at the University Hospital of Brazzaville in the Republic of Congo. We performed a prospective study within a period of six months, into the surgical unit of the emergency department of the University Hospital of Brazzaville. A total of 2617 patients were recorded, among which 268 cases were TBI (10.25\%) where 142 cases were sampled in our series. The average age was $36.7 \pm 16.6$ years. The sex ratio was 6.1. The TBI was mainly due to road accident in 121 cases (85.2\%) described as follows: motorcycle accident about 48 cases (39.7\%) and the pedestrian's injuries about $42(34.8 \%)$. In the majority of the cases, cautions were not taken by the drivers; during the case of the motorcycle accident, about $97.9 \%$ of the riders did not wear a helmet. The TBI remains a growing public health concern in the low-income countries, like in Africa. Measurements on the road traffic regulation are to be strengthened to reduce the growth of this silent epidemic.
\end{abstract}

\section{Keywords}

Traumatic Brain Injury, Road Accident, Brazzaville

\section{Introduction}

Traumatic brain injury (TBI) is often referred to as the "silent epidemic" and 
remains a growing public health concern. It is considered as the greatest contributor to death and disability among all trauma-related injuries [1] [2]. The global incidence of all-cause and severity TBI is estimated at 939 cases per 100,000 people and it is estimated that 69.0 million people worldwide will suffer TBI each year. The vast majority will be mild ( $81 \%)$ and moderate (11\%) in severity [3].

The epidemiological estimate of TBI from low and middle-income countries like in Africa is limited by relatively low-quality data and suggests the need of more robust and accurate injury reporting [3]. Sub-Saharan Africa demonstrates a higher head injury related incidence rate varying from 150 to 170 per 100,000 respectively due to motor vehicular crashes compared to a global rate of 106 per 100,000 [4]. Road traffic collisions are a significant source of TBI [5]. While guidelines have been established for the care of patients with severe head injury, these protocols require some of the most expensive resources of a high-income country, such as CT imaging and neurosurgical capabilities. Even the World Health Organization (WHO) recommendations for the Essentials of trauma care recognize that it is unlikely that low- or middle-income countries will be able to meet these guidelines fully. Low income nations can focus on implementing pre-hospital care training [6]. In the Republic of Congo, hospitalization frequency is estimated at $39.95 \%$, with the average age of 31.26 years old and mortality of $10 \%$ [7].

The aim of this study was to evaluate the socio-demographic profile of adults admitted in emergency for TBI at the University Hospital of Brazzaville in order to improve our knowledge about TBI circumstances in the sub-Saharan countries.

\section{Material and Methods}

We performed a descriptive and prospective study, within a period from $30^{\text {th }}$ November 2017 to $30^{\text {th }}$ May 2018 (six months) into the surgical unit of emergency department of the University Hospital of Brazzaville who is the national reference center for management of neurosurgical diseases. We selected among all patients admitted in the department of emergency, cases from 18 years old and more hospitalized for TBI. We excluded cases of subdural hematoma and death at arrival. The parameters evaluated were age, sex, origin and traumatic circumstances. The circumstances of the trauma were defined by the event in question, position of the patient (motorcyclist, driver or passenger in a car, pedestrian) and the type of collision (example: motorcyclist versus pedestrian). The interrogation was conducted with the patient or his entourage. After clinical examination, the data were recorded during the continuation of management. Collection of data was performed from hospital register, medical file and fact sheet prepared for codification, and treated in Excel 14.2.0 (120402).

\section{Results}

During the period of study, 2617 patients were recorded in the surgical unit of the emergency department of the University Hospital of Brazzaville. Among 
these 2617 cases, 268 (adults and children) were admitted for TBI (10.25\%) and 142 were included in our series (5.42\%). The other cases were children (106 cases), subdural hematoma (11 cases) and death at arrival (9 cases).

Table 1 below indicates ages of patients. The average age was $36.7 \pm 16.6$ years, with extremes between 18 and 82 years. We recorded 122 men against 20 women with a sex ratio of 6.1.

The majority of the patients: 90 cases (63.4\%) have a secondary level of school instruction; 29 cases $(20.4 \%)$ have a primary level; 20 cases have university level and at last three cases (2.1\%) with no educational background.

Table 2 below indicates professions of patients.

In our series, TBI were due to road accident in 121 cases (85.2\%), followed by assaults (9.9\%), falls $(4.2 \%)$ and sport accident $(0.7 \%)$. Table 3 below indicates collision circumstances during road accident. Among cases of road accident, 48 patients were riders (39.7\%), followed by 42 pedestrians (34.8\%), 22 car passengers (18.1\%) and nine car drivers (7.4\%). In the group of riders (48 cases), 47 cases did not wear a helmet (97.9\%). In the group of 31 patients in the car (passengers or drivers), only eight cases (25.8\%) wore a seatbelt. Among 121 cases of road accident, only 68 vehicles $(56.2 \%)$ had insurance and two patients $(1.4 \%)$ had health insurance. Only one patient received medical transport, but no neck brace.

Table 1. Age of patients.

\begin{tabular}{ccc}
\hline & $\mathrm{n}$ & $\%$ \\
\hline $18-24$ & 28 & 19.7 \\
$25-34$ & 54 & 38.0 \\
$35-44$ & 23 & 16.2 \\
$45-54$ & 20 & 14.1 \\
$\geq 55$ & 17 & 12.0 \\
Total & 142 & 100 \\
\hline
\end{tabular}

Table 2. Professional status of patients.

\begin{tabular}{ccc}
\hline & $\mathrm{n}$ & $\%$ \\
\hline Informal activity & 69 & 48.6 \\
Students & 31 & 21.8 \\
Private employed & 9 & 6.3 \\
Fonctionary & 15 & 10.6 \\
Without & 18 & 12.7 \\
Total & 142 & 100
\end{tabular}


Table 3. Collisions circumstances during road accident.

\begin{tabular}{ccc}
\hline & $\mathrm{n}$ & $\%$ \\
\hline Motorbike versus car & $\mathbf{3 4}$ & $\mathbf{2 8 . 1}$ \\
Car versus pedestrian & 34 & $\mathbf{2 8 . 1}$ \\
Motorbike versus pedestrian & 17 & 14.0 \\
Motorbike alone & 14 & 11.6 \\
Car alone & 13 & 10.7 \\
Motorbike versus Motorbike & 5 & 4.2 \\
Car versus car & 4 & 3.3 \\
Total & 121 & 100 \\
\hline
\end{tabular}

\section{Discussion}

The aim of this study was to first of all appreciate the type of patients admitted in emergency for TBI in Republic of Congo. The study actually revealed how improving road traffic regulations can heavily prevent TBI cases related to road accident. However, this study can be improved by elaborating a "National Register of TBI" in order to see whether the actual TBI profile can be extended in the entire country.

Hospitalization frequency of TBI in our series was $10.25 \%$. Between 2014 and 2015, we found a frequency of $31.17 \%$ [8]. Despite a considerable reduction, improvements are still to be done compared to similar studies performed elsewhere. In this series, frequency integrates all adult patients admitted in the emergency department within the period of study so the case of the study performed on patients admitted in the surgery department in Cameroun (Central Africa) Motah et al. [9] where the hospitalization frequency was $5.15 \%$ and in Mali (West Africa) Coulibaly et al. [10] where the hospitalization frequency was $5.9 \%$. From a projection model, the potential future burden of TBI in Africa will be the highest in eastern and western Africa for men aged between 15 and 34 years. TBI will be a leading cause of morbidity and mortality globally by the year 2020 , particularly in low- and middle-income countries; Africa possesses $4 \%$ of motor vehicles in the world but already one-tenth of deaths are caused by motor-vehicular injuries [11] [12]. The total estimated TBI count in Africa in 2050 is $5.98 \pm 0.03$ million, with the highest count in eastern Africa at $0.15 \pm 0.00$ million [12].

Most of patients in our series have 18 to 34 years old. However, the group between 25 to 34 years old was the most important. Average age was $36.7 \pm 16.6$ years, with extremes between 18 and 82 years. We didn't included children in our study. Motah et al. [9] found an average of 28.33 years old and $54.32 \%$ between 30 and 57 years old. TBI counts stratified by age in Africa in 2050 are also estimated highest for males aged 15 - 34 [12]. TBI are major cause of morbidity and mortality in young adults [13].

Sex ratio in our study was 6.1 . The gender ratio ranged considerably, from 
1.81:1 in South East Finland to 4.81:1 in South Africa [14]. Mind Li et al. [14] found in a systematic review that the men were at a higher risk of TBI than women. Kraus et al. [15] found that the mortality rate of women compared to men suffering from TBI was 1.28 times higher on average.

In our series, TBI were due to road accident in 121 cases (85.2\%). Main authors report that road accident is the most frequent cause of TBI [12]. Riders (39.7\%) and pedestrians (34.8\%) were the most frequent among victims of TBI in our series. Motah et al. [9] found $74.07 \%$ of patients using bicycles. Urbanization in Africa will increase the rate of TBI by road accident. In a study performed in Kenya, comparing values from 2004 to 2009, there was an increase in motorcyclist road traffic injury (29\%) and overall fatalities (7\%) within that 5 -year timeframe [16]. This frequency indicates the necessity to improve regulation on road traffic in our countries. In the group of riders $97.9 \%$ do not wear a helmet. In the group of patients in the car (passengers or drivers), only $25.8 \%$ wore a seatbelt.

\section{Conclusion}

TBI represents an important part of patients admitted in emergency in the university hospital of Brazzaville (10.25\%) in the Republic of Congo. Most of them are due to road accident $(85.2 \%)$ and mainly concern young male people. Predicting data estimates increasing of TBI in Africa in 2050 and thereabout. Measurements on the road traffic regulation are to be strengthened to reduce the growth of this silent epidemic.

\section{Conflicts of Interest}

The authors declare no conflicts of interest regarding the publication of this paper.

\section{References}

[1] Rusnak, M. (2013) Traumatic Brain Injury: Giving Voice to a Silent Epidemic. Nature Reviews Neurology, 9, 186-187. https://doi.org/10.1038/nrneurol.2013.38

[2] Rubiano, A.M., Carney, N., Chesnut, R. and Puyana, J.C. (2015) Global Neurotrauma Research Challenges and Opportunities. Nature, 527, 193-197.

https://doi.org/10.1038/nature16035

[3] Dewan, M.C., Rattani, A., Gupta, S., Baticulon, R.E., Hung, Y.-C., Punchak, M., Agrawal, A., Adeleye, A.O., Shrime, M.G., Rubiano, A.M., Rosenfeld, J.V. and Park, K.B. (2018) Estimating the Global Incidence of Traumatic Brain Injury. Journal of Neurosurgery, 4, 1-18. https://doi.org/10.3171/2017.10.JNS17352

[4] Odero, W., Garner, P. And Zwi, A. (1997) Road Traffic Injuries in Developing Countries: A Comprehensive Review of Epidemiological Studies. Tropical Medicine \& International Health, 2, 445-460. https://doi.org/10.1111/j.1365-3156.1997.tb00167.x

[5] Masson, F., Thicoipe, M., Aye, P., Mokni, T., Senjean, P., Schmitt, V., Dessalles, P.H., Cazaugade, M., Labadens, P., Aquitaine Group for Severe Brain Injuries Study. (2001) Epidemiology of Severe Brain Injuries : A Prospective Population-Based 
Study. The Journal of Trauma, 51, 481-489.

https://doi.org/10.1097/00005373-200109000-00010

[6] Qureshi, J.S., Ohm, R., Rajala, H., Mabedi, C., Sadr-Azodi, O., Andrén-Sandberg, A. and Charles, A.G. (2013) Head Injury Triage in a Sub Saharan African Urban Population. International Journal of Surgery, 11, 265-269. https://doi.org/10.1016/j.ijsu.2013.01.011

[7] Ekouele Mbaki, H.B., Boukassa, L., Ngakosso, O.B., Kinata Bambino, S.B., Elombila, M. and Moyikoua, R. (2016) Neurosurgery Practice at the University Hospital of Brazzaville (Congo): 21 Months of Activity. African Journal of Neurological Sciences, 35, 47-54.

[8] Ekouele Mbaki, H.B., Otiobanda, G.F., Elombila, M., Boukassa, L., Moyikoua, R., Gombet, T.R. and Okiemy, G. (2016) Traumatic Brain Injuries in Adults: Epidemiological Aspects and Management at the University Hospital of Brazzaville (Congo). Revue Africaine d' Anesthésiologie et Médecine d Urgence, 21, 27-32.

[9] Motah, M., Sende Ngonde, C., Beyiha, G., Bellen Priso, E., Malongte Nguemgne, C., Gonsu Fotsin, J., Verbova, L.N. and Ebana Mvogo, C. (2011) Management of Isolated Brain Trauma Injuries at General Hospital of Douala. Health Sciences and Diseases, 12, 1-6.

[10] Coulibaly, Y., Mp, E., Diallo, A., Doumbia, D., Keita, M., Keita, A., Diallo, A., Diango, D.M., Ongoïba, N., Diallo, G. and Sidibe, S. (2004) Head Trauma in the Hospital du Point G: About 80 Cases. Mali Médical, 19, 3-4.

[11] Saidi, H., Ben Kasyoka, M. and Ogengo, J. (2014) Mortality after Road Traffic Crashes in a System with Limited Trauma Data Capability. Journal of Trauma Management and Outcomes, 8, 4. https://doi.org/10.1186/1752-2897-8-4

[12] Wong, J.C., Linn, K.A., Shinohara, R.T. and Mateen, J. (2016) Traumatic Brain Injury in Africa in 2050: A Modeling Study. European Journal of Neurology, 23, 382-386. https://doi.org/10.1111/ene.12877

[13] Mac Kenzie, E.J., Siegal, J.H., Shapiro, S., Moody, M. and Smith, R.T. (1988) Functional Recovery and Medical Costs of Trauma: An Analysis by Type and Severity of Injury. Journal of Trauma-Injury Infection \& Critical Care, 28, 281-297. https://doi.org/10.1111/ene.12877

[14] Li, M., Zhao, Z., Yu, G. and Zhang, J. (2016) Epidemiology of Traumatic Brain Injury over the World: A Systematic Review. Austin Neurology \& Neurosciences, 1, 1-14. https://doi.org/10.4172/2327-5146.1000275

[15] Kraus, J.F., Peek-Asa, C. and McArthur, D. (2000) The Independent Effect of Gender on Outcomes Following Traumatic Brain Injury: A Preliminary Investigation. Neurosurgical Focus, 8, 1-7. https://doi.org/10.3171/foc.2000.8.1.156

[16] Bachani, A.M., Koradia, P., Herbert, H.K., Mogere, S., Akungah, D., Nyamari, J., Osoro, E., Maina, W. and Stevens, K.A. (2012) Road Traffic Injuries in Kenya: The Health Burden and Risk Factors in Two Districts. Traffic Injury Prevention, 13, 24-30. https://doi.org/10.1080/15389588.2011.633136 